Please note that all letters must be typed. Priority will be given to those that are less than 500 words long. All authors must sign the letter, which may be shortened or edited for reasons of space or clarity. All letters received are acknowledged.

\section{Medical emergencies}

Sir, - We read with interest the article by Atherton, Pemberton and Thornhill (BDJ 2000; 188: 320-324) regarding medical emergencies at a UK dental hospital.

We were interested to note that the staff surveyed felt they needed further training to improve their readiness to manage medical emergencies. In a confidential survey ${ }^{1}$ of the cardiopulmonary resuscitaion (CPR) training of SHO's in oral and maxillofacial surgery in the UK, we reported dissatisfaction with CPR training.

Of respondents, $91.5 \%$ would have liked further CPR training, with many requesting Advanced Cardiac Life Support training, as opposed to Basic Life Support which was the level to which most had been trained. As a result of the survey, we made the following recommendations:

(a) There should be regular training in CPR for all dental staff, ideally at sixmonthly intervals.

(b) The syllabus for dental postgraduate examination should continue to include CPR.

(c) Further training should be guided by audit of CPR skills.

It would seem appropriate to apply these recommendations to dental staff, both in general practice and hospital employment. We intend to report the findings of a followup survey of SHO's resuscitation training in the near future.

G. S. Bassi, G. C. S. Cousin, J. C. Lowry Leeds, Manchester, Blackburn

1 Cousin G C S, Bassi G S, Lowry J C Cardiopulmonary resuscitation training of SHO's in Oral and Maxillofacial Surgery in the UK. Br J Oral Maxfac Surg 1999; 37: 1

\section{Quick Fix?}

Sir, - Parts of Dr. Rob Chate's article (BDJ $2000 ; 188: 177-186$ ) amount to a criticism of rapid maxillary expansion (RME) in general and my work in particular by a tactic of selecting pieces from the literature that suited the author' s idée fixe.

There is nothing wrong in dilation of stenosed ducts as widening improves the flow, it has a long history in medicine and in use today, e.g. angioplasty in coronary heart disease. Dr. Chate does not equate resistance to obstruction, yet when ENT sur- geons speak of resistance they mean difficulty in nasal breathing due to obstruction. This parameter (resistance) can be measured and used as an index of airway efficiency. ${ }^{1}$ In the absence of some evident obstruction such as adenoids, the narrowest part of the nasal airway is usually the valve and being situated at the lower anterior end ${ }^{2}$ it benefits from RME.

Studies ${ }^{3,4}$ that claim an unpredictability in RME have misinterpreted their results and one is reminded of Mills' Dictum ${ }^{5}$ : torture the data enough and it will tell you anything. The samples used in these studies show a wide range of pre-treatment resistance values, some so low to be near normal, yet all were subjected to a similar RME $(7-8 \mathrm{mms})$. Matching reductions in resistance values could not possibly be not obtained. Had the reductions in resistance been compared with the pre-treatment values, the correlation would have been very strong. My own results gave a high coefficient $(r)$ of 0.92 . In other words, the high resistance cases achieved the greatest reductions and most finished treatment within normal levels: eminent predictability.

We are informed that RME only increases the airway width by $1 \mathrm{~mm}$ but the nasal valve and common meati are vertical apertures normally 2-3 mms wide, so an expansion of $1 \mathrm{~mm}$ would be significant.

RME exerts a force of $12-23 \mathrm{lbs}$ at the teeth $^{6}$ which opens the palatine suture, moving the maxillary and palatine bones laterally. Some of this movement is carried to the sphenoid and being a single bone, the pterygoid processes are slightly bent. This is apparent at the hamuli and their positions just beneath the mucosa allows their distance apart to be measured. With a little practice, this can be done to about $0.5 \mathrm{~mm}$ using calipers, a negligible error when the inter-hamular width increases by $4 \mathrm{~mm}$ during RME. ${ }^{7}$ Dr. Chate questions its effect on Eustachian tube function: the tensor palatine muscle is primarily responsible for opening the tube $e^{8}$ and its middle tendon slings around the hamulus. Lateral movement of the hamulus will tighten the muscle and increase the pull. ${ }^{9}$ Animal work revealed symptoms of otitis media where these tendons had been transposed medially, i.e. slackening the muscle. ${ }^{10}$

Nasal obstruction causes subjects to mouth breathe ${ }^{11}$ when much of the inspired air by-passes the defense mechanisms for warming, humidifying and filtration built into the nose. The respiratory tract is opened to inflammatory conditions including otitis media via the Eustachian tube. ${ }^{12}$

On the matter of anecdotes, the majority of my cases were monitored by ENT surgeons and it saddened me to read Gray's (ENT surgeon $)^{13}$ large prospective analysis marginalised. If Dr. Chate wants longitudinal studies with controls, read Markwardt's ${ }^{14}$ multi-disciplinary research or Griffin's ${ }^{15}$ nasal eosinophil counts, both are a credit to RME.

\section{J. Timms}

\section{Bournemouth}

1 Cole P. Respiratory rhinometry, a review of recent trends. Rhinol. 1980; 18:3

2 Haight J S J, Cole P. Site and function of the nasal valve. Laryngoscope. 1983; 93: 49-55.

3 Hartgerink D V, Vig P, Abbot D. Effect of rapid maxillary expansion on nasal airway resistance. Am J Orthod Dentofac Orthop. 1987; 92:381-9

4 White B C, Woodside D, Cole P. Effect of rapid maxillary expansion on nasal airway resistance. J Otolaryngol. 1989; 18: 137-43

5 Mills J L Data torturing. New Eng J Med. 1993; 329:1196-9.

6 Issacson R J, Ingram A. Forces produced by rapid maxillary expansion. Angle Orthod. 1965; 35:26 1-70.

7 Timms D J A study of basal movement with rapid maxillary expansion. Am J Orthod. 1980; 77: 500-7.

8 Honjo I, Okozaki N, Kumazawa T. Experimental study of the Eustachian function with regard to its related muscles. Acta Otolaryngol. 1979; 87: 84-9.

9 Close R I. Dynamic properties of the mammalian skeletal muscles. Physiol Rev. 1972; 52: 129-74.

10 Cantekin E I, Phillips D, Doyle W, Bluestone C, Kimes K. Effect of surgical alterations on the tensor veli palatini muscle on Eustachian tube function. Ann Otol Rhinol Laryngol. 1980; 89 (sup.):47-53

11 Niinimaa V, Cole P, Mintz S, Shepard R. The switching point from nasal to oronasal breathing. Respir Physiol. 1980; 42: 61-71.

12 Giebink G S. Prevention and treatment of otitis media. In: Kavanagh J K (ed) Otitis Media and Child Development. Parkton, MD. York Press 1968, 178.

13 Gray L P. Results of 310 cases of rapid maxillary expansion selected for medical reasons. $J$ Laryngol Otol. 1975; 89: 601-4.

14 Markwardt A W. Vorlaufige Erfahrungen uber die Auswirkung der Gaumennahterweiterung auf das Hilfsshulkind. Forts Kieferorthop. 1961; 22: 359-64.

15 Griffin C J. Subluxation of the vomeromaxillary articulation and its effect on tissue and peripheral eosinophilia. Aust Dent J. 1961; 6: 498-200.

The author Dr R. A. C. Chate responds: Donald Timms is mistaken in his belief that the section on 'Maxillary expansion improves ENT pathology' in my review is a criticism of RME. He also accuses me of criticising his work in particular, when in fact my comments were merely a reproduction of his own self criticisms. ${ }^{1}$

He accuses others of data misinterpretation and torturing, and suggests that had these data been analysed in the way he describes, a different conclusion would have been drawn. If he reads the articles more carefully he will see that the data was indeed analysed in the way he has recommended, both in comparison to the before and after RME Nasal Airway Resistance (NAR) means, as well as to the individual pre and post 
treatment values, and that high correlations were found between the initial NAR and the magnitude of reduction in NAR ( $\mathrm{r}=0.9)$ for individuals, such that the best predictor for reducing NAR with RME would seem to be a high pre-treatment level of resistance. ${ }^{2}$

That RME can reduce nasal resistance, and that it most likely does this by dilating the anterior nares was outlined in the review, and is not in dispute. However, I merely reported the contention that others have expressed, in that it does not always do this ${ }^{3}$, and that even so, reducing NAR does not guarantee that a mouth breather will revert to a normal pattern of nasal respiration. ${ }^{2,3}$

The relevance of this is in the interception of the growth of an individual with Long Face Syndrome, when an open mouth posture adopted for oral respiration facilitates a supposition vertical pattern of mandibular development and an anterior open bite. The supposition that reduction of NAR through expansion reverses this remains unproven. With regard to the issue of maxillary expansion reducing the incidence of otitis media, even if RME does produce lateral separation of the hamuli, would this result in the tensor palatine muscles being stretched?

Common sense would seem to indicate so, but as in other areas of research, clinical assumptions based on this can be fundamentally flawed.

For example, until recently, most clinicians would have expected that transient bacteraemias produced after gingival manipulation would have been more profound in those individuals with gingivitis compared to those without. ${ }^{4}$

It should therefore be clear that each of the five steps of the entirely plausible hypothesis that: (a) RME bends the hamuli laterally, (b) which stretches the tensor palatine muscles, (c) which opens the Eustachian tubes, (d) which improves functional drainage, (e) which reduces the incidence of otitis media, needs to be objectively assessed with prospective randomised controlled trials, if the truth is ever to be known.

He describes Gray's work as a large prospective which he feels has been marginalised. Indeed, 310 patients were evaluated, but apart from 70 who had pre and post expansion PA tomograms measured, for which no data were presented other than a list of eight 'improvements,' essentially the study consisted of the response from $92 \%$ of the parents who replied to a retrospective questionnaire about six months later.

While the conclusions based on the subjective improvements that were reported for the children's 'airway, infections, sniffing and itching, wheezing and psychological' would have sufficed when the paper was first read in 1973, the fact that this study was not prospective, that patients were not randomly allocated either to the experimental expansion group, or a non-expansion control, that the patients were not kept blind to the possible benefits, and that no objective measurements were taken, means that unfortunately the 'results' are of little value.

He recommends two papers of longitudinal studies with controls, but Markwardt's is written in German with no English abstract, while Griffin's is only a report of three cases in whom the blood and mucous eosinophil counts rose after RME, supposedly indicative of a 'cure of the allergic condition.'

He accuses me of being selective with the evidence presented to support my own fixed ideas, when in truth, the only difference between us seems to be in the level of evidence that is required to satisfy us on this issue; of the three verdicts available in Scottish law. For the present, mine would still have to be 'Not Proven.'

1. Timms D J. A study of basal movement with rapid maxillary expansion. Am J Orthod 1980; 77: 500-507.

2. White B C, Woodside D. G, Cole P. The effect of rapid maxillary expansion on nasal airway resistance. J Otolaryngol 1989; 18:137-143.

3. Hartgervink D V, Vig D S, Abbott D W. The effect of rapid maxillary expansion on nasal airway resistance. Am J Orthod Dentofacial Orthop 1987; 92: 381-389.

4. Roberts G J, Gardener P, Longhurst P, Black A E, Lucas V S. Intensity of bacteraemia associated with conservative dental procedures in children. Br Dent J 2000; 188: 95-98.

\section{Orthodontics on TV}

Sir, - I would like to add to some observations following the recent flurry of TV programmes on the subject of orthodontics.

One of the main participants in these programmes (Dispatches, London Today etc) is Mr Mew, who is not slow to show what he feels is a ruined face following orthodontic treatment. It is a giant leap to conclude from one or two badly treated cases that all orthodontics is therefore going to spoil patients profiles.

Can we ask Mr Mew to submit 100 consequtively treated cases of his own for scientific evaluation? It would be nice to quantify his success and failure rates and perhaps see the profile changes that he has managed on his own patients.

Mr Mew often claims that his views are suppressed by the dental magazines. I am sure that we are all familiar with his views let us see his results.

I would also like to add that it is regrettable that this sort of argument is brought into the public domain and not kept within the profession. To do otherwise, results in patients being needlessly alarmed and many of us have been asked by anxious patients for their children to have fixed braces removed in the middle of a course of treatment, despite their treatment being incomplete.

\section{T. Pollard}

Sutton

Sir, - J. Misner (BDJ 2000: 188: 471) rightly condemns the recent Dispatches programme regarding orthodontics as irresponsible and sensationalist. It may interest readers to know that I was approached by the producer of the programme and agreed to appear on condition that I could have complete and unrestricted access to $\mathrm{Mr}$ Mew's records in order to form an opinion and debate his claims. This request was denied. Given that it was impossible for me to comment about treatment philosophies that I was denied access to, I declined to appear.

The excellent review of the literature by Mr R Chate (BDJ 2000: 188: 177-186) neatly summarises contemporary opinion. The beautifully written article summarises worldwide scientific research and directly refutes some of the claims being made in the Dispatches programme. Sadly, the general public do not pick up the $B D J$ and I have even had one patients' parent exclaim to me that 'it must be true because I saw it on the telly.' The programme has certainly persuaded patients throughout the country that their appliances should be removed before their treatment is complete. I feel that the makers of the programme and its participants should have been aware of the possible consequences for these patients and that their decision to proceed is deeply regrettable.

Interestingly, Mr Mew, one of the main participants in the programme, claimed that his work was being ignored or even suppressed. In fact, Mr Mew has been invited to release his results, most recently, to Manchester University, who are carrying out a scientific comparison of treatment techniques. He seems surprisingly reluctant to release material.

\section{P. Cornish \\ Leeds}

\section{Oral cancer screening}

Sir, - We read with interest the recent supplement to the $B D J$ on 'Opportunistic oral cancer screening. Once again, the BDA are reminding the dental profession of the need to be vigilant and providing the dental team with the tools needed to achieve a high measure of success in screening for oral cancer.

We are concerned about the prominence given to the use of tolonium blue (in all previous publications called toluidine blue) as a vital agent in the process of oral screening. In the 31-page issue, it is mentioned on 15 
pages and, in total, three full pages are devoted to its use. Concerns were raised about its use in general dental practice by Richards et al ${ }^{2}$ after the last BDA occasional paper on oral cancer issue where toluidine blue was also advocated and these have still not been adequately addressed. The questions we are asking in relation to its use are: what is the specificity and sensitivity and predictive value of this test in the general population, how acceptable is its use by GDPs in routine dental patients and what is its cost effectiveness ( $£ 16.20$ a single use kit and not reimbursable on the NHS)?

We will attempt to answer these questions from the available literature as, in theory, all new tests and procedures should be fully evaluated in randomised controlled trials or in comparison to a gold standard before being advocated for use and any review of the literature should be systematic and include explicit criteria for inclusion and exclusion of papers. Epstein et al ${ }^{4}$ in their paper of 1997 (quoted in the supplement) write in their discussion:

There are currently no studies that provide data regarding the use of toluidine blue by less experienced providers and therefore the sensitivity and specificity, and predictive value in these clinical settings is not known. It is also not known whether the more widespread use of toluidine blue in general dental practice or as a screening tool will result in an increased diagnosis of dysplasia and malignancy or will result in increasing numbers of biopsies of benign mucosal changes.

Psychological trauma is inevitable, especially as there is a two week gap between tests. In a patient with a true positive at the first testing there is a further unnecessary two-week delay prior to being seen by a specialist.

A further paper published in 1998 on its use in lesions with epithelial dysplasia is not quoted in the supplement (bias on the part of the authors). ${ }^{5}$ In this paper, the authors make the following statement in the abstract 'the false negative rates of $42 \%$ and $58 \%$ obtained for carcinoma in situ and mild to moderate dysplasia respectively suggest restricting the use of vital staining to selective cases.'

Warankulasuriya and Johnson ${ }^{6}$ quote much lower figures for false results but their patients all had oral mucosal lesions and were Asian patients at high risk of oral cancer. Martin et $a l^{5}$ point out that the low prevalence of malignant disease in the general population and the high false positive and false negative rates may make the use of the dye more confusing for general practitioners as it may not correlate with their clinical findings. As far as we are aware there have not been any further published studies on the use of the stain in the general practice setting. Frictional keratosis and all ulcerated lesions including erosive lichen planus and herpetic lesions stain positive and so need to be recognised by the practitioner as they are commoner than oral cancer. The acceptability of the dye was tested only in a chain of retail stores that had been running an oral cancer screening programme for many years, where practitioners had been specifically trained and it was free. ${ }^{7}$ The results are therefore not representative of the general population. The cost of training and administering the test has not been considered and yet it is the patients at most risk of oral cancer who are least likely to be willing to pay for the test. The burden to specialist centres of increased referrals also needs to be assessed.

We have failed to find the evidence for the efficacy and cost effectiveness of toluidine blue in general dental practice when used by GDP. Should we be endorsing its use in GDP at this point in time given the lack of evidence? From this second supplement, it would appear that it is endorsed.

\section{J. M. Zakrzewska, I. C. Martin Sunderland}

1 British Dental Association Occasional Paper BDA 2000, Issue 6

2 British Dental Association Occasional Paper BDA 1998, Issue 5

3 Richards D, Lawrence A, Thomas D T Toluidine Blue, BDA News 1998 ;11:4

4 Epstein J B, Oakley C, Miliner A, Emerton S, Van der Meij E, Le N. The utility of toluidine blue application as a diagnostic aid in patients previously treated for upper oropharyngeal carcinoma. Oral Surg Oral Med Oral Pathol Oral Rad Endod. 1997; 83: 537-547.

5 Martin I C, Kerawala C J, Reed M. The application of toluidine blue as a diagnostic adjunct in the detection of epithelial dysplasia. Oral Surg Oral Med Oral Pathol Oral Rad Endod. 1998; 85: 444-446.

6 Warnakulasuriya K A, Johnson N W. Sensitivity and specificity of OraScan (R) toluidine blue mouth rinse in the detection of oral cancer and precancer. J Oral Pathol Med 1996; 25: 97-103.

7 Feaver G P, Morrison T, Humphris G. A study to determine the acceptability in patients and dentists of toluidine blue in screening for oral cancer. Prim Dent Care. 1999; 6; 45-50

Sir, - Whilst welcoming the new BDA occasional paper (number 6) on 'Opportunistic Oral Cancer Screening', and the importance it places on a full soft tissue examination, we were concerned to note the implied endorsement of the use of toluidine blue (tolonium chloride) as an adjunct to this examination.

We have recently completed a systematic review of the use of toluidine blue as an adjunct to oral cancer screening and have found little evidence to suggest that toluidine blue is a cost-effective method of picking up oral cancers in a primary care setting. Case series reports of the use of toluidine blue in secondary care show variable results in terms of the sensitivity and specificity of the test, however, in general, the quality of these studies is poor.

The results of studies in secondary care relate to the test characteristics of toluidine blue as a screening test for oral cancer in people with detected oral lesions and are not generalisable to primary care. Given the large number of people that will have false positive rates for a first positive test and even a double positive test, the harm of using it in terms of anxiety could well outweigh the benefits in terms of additional cancers detected.

At a time when the profession is being encouraged to practice evidence-based dentistry, we consider it to be quite inappropriate for the BDA to be seen as endorsing a procedure for which there is little scientific evidence. We will be submitting a paper to the journal presenting the results of our systematic review in the near future.

\section{Gray, K. Elley \\ Walsall, Sandwell}

The editors of the Occasional Paper (Geoffrey Craig and Newell Johnson) write: The paper does not endorse the general use of tolonium chloride in primary care but discusses its use in relation to high risk groups. Rather than the systematic review reported by Drs Gray and Elley, the real need now is for further studies in normal rather than high risk populations. One such study is just about to start.

In the meantime, we suggest that there is not the evidence to rule out the use of tolonium chloride in primary care, as these correspondents are doing. Practitioners can make their own judgements. The Occasional Paper was an attempt to help them to do that.

Dr Zakrezewska and Mr Martin widen the discussion to take in cost-effectiveness. While the NHS may attempt to use its resources with total rationality, this should not set limits on what dentists can offer their patients directly. In the end, people paying the bill decide what constitutes value for money and it is a dangerous philosophy to say that things which are not completely established cannot be offered.

\section{NHS Direct}

Sir, - While working in a busy district general hospital accident and emergency department, I often saw patients attending inappropriately with dental problems most commonly toothache and dental abscesses.

I was therefore relieved when the government introduced the NHS Direct service, the aim of which was to advise patients over the telephone on medical and dental problems and therefore decrease the burden on general practitioners and accident and emergency departments. 


\section{OPINION $\underline{\text { letters }}$}

I audited the number of dental patients attending our department for five months (October 1998 to February 1999) before the introduction of NHS Direct and the same months in 1999-2000 after the commencement of the service.

The results were disappointing, the numbers being 51 patients attending with dental problems in 1998-99 and 52 patients in 1999-2000. We can therefore conclude that NHS Direct has made no impact on patients attending with dental complaints in our accident and emergency department.

\section{Kumar}

Colchester

\section{HRT ulceration}

Sir, - May I use the letters column of the Journal to highlight an occasional finding with aphthous ulceration I have noticed with ladies taking Hormone Replacement (HRT) to mitigate menopausal symptoms.

When HRT was withdrawn, for whatever reason, the aphthous ulceration the women had been plagued with before starting therapy returned and ulcerations stopped.

A pharmacist colleague of mine, through his drug information officer, located two references to 'improved mouth comfort' with HRT therapy but not specifically for ulceration.

Could an effective treatment modality along these lines be found which could alleviate the ulceration suffered by so many? Perhaps not for the male of the species!

\section{B. Williams}

Banstead

\section{Room with a view}

Sir, - The March issue of $B D A$ News rather interestingly devoted two contrasting sections to the topic of dentistry abroad. The section 'So you want to work abroad' concentrated on developed countries, while Stuart Robson's article 'President sees the big wide world' focused on his first visit to the Indian sub-continent to attend the Commonwealth Dental Association meeting.

I appreciated Dr Robson's comment that his perspective on life in general has undergone a subtle change after his trip to India. South-Asian lifestyles and healthcare needs can overwhelm at first sight. 'Where on earth do I start?' is quite a normal reaction.

Stuart's view of the population seeming relatively content with their lot in life is almost plausible. One can reach that conclusion on a short trip. Perhaps it also acts as a brake on one's emotions when faced with apparently overwhelming odds. Prompted by the suggestion in this article that Western dentists should consider donating a few weeks or months in the developing world, I would like to move the argument on a little further.

Two-thirds of the world's healthcare professionals work amongst one-third of the world's population. There is an immediate equity problem. This is evidence-based. Over time, many dentists have visited us in Nepal keen to give a fortnight of their time gratis to assist our work. It sometimes helps us. But, if the truth be told, it is normally the dentist who returns to Europe, the States or the Antipodes feeling best about it with conscience more appeased. Why not commit? Give some years rather than weeks or months?

Evidence shows (in most cases) the increased effectiveness of the former. Language and orientation - dentists need string to tie their hands together rather than kit with which to 'treadmill' into a very different scenario - are fundamental to benefactor and beneficiary.

The gain from the pain makes for added value. The greater emphasis in poor countries on verbal communication rather than www.speech.com and the reprioritisation of life's expectations away from (virtually) allpervasive consumerism can rejuvenate the belief in the primary importance of people. Yes, there is noise and dirt and chaos. Goats lose their heads where the school bus collects our kids. But families grow in such an extraordinary environment. Amidst the differing freedoms and restrictions, we imbibe far more than we can give.

In being real about the real world, sentimentality must give way to seriousness in the same way we become serious about the fee-scale or the impact of clinical governance. Dentists, by virtue of their reasonable income and lifestyle which Stuart Robson alludes to, are in a favoured position when it comes to choosing a departure gate at Heathrow.

It is often cited that busy practices need to be run. Must they? By choice or by default? Whispers are frequently heard from those who declare their willingness to work in needy lands once they have educated their children. With which tranche of working energy?

Nepal has a population of 23 million people and around 100 dentists, 92 of whom work in the Kathmandu Valley with less than $4.5 \%$ of the customers. That is another problem. Look elsewhere in two-thirds of the world and the picture is largely similar.

Many issues must be carefully assessed before a decision is made to live in this arena but the benefits outweigh the apparent sacrifices. Stretching is in the job description. Personal growth is guaranteed. In BDJspeak, there is a book of wonderfully grateful patients and full clinical freedom.
Immediate start preferred. For more details contact Neil McDonald, Director, Oral Health Programme, United Mission in Nepal, PO Box 126, Kathmandu, Nepal.

\section{N. McDonald} Nepal

\section{Piercing dangers}

Sir, - As the fashion for body piercing continues, the following case may be of interest to other dentists.

A patient attended as an emergency claiming that she had fractured a tooth. She had a stud in her upper lip above the left angle. This was held in place by a metal disk on her inner lip. The stud had been placed two months previously.

Intra-orally, the buccal cusp of her upper left second premolar had fractured. The tooth had a large MOD amalgam restoration which had been in place undisturbed for over five years. The patient's upper left first premolar and upper left first molar had shell crown restorations. The metal disk was in close proximity to the second premolar at rest and passed over the buccal surface when the patient smiled. It would appear that the metal disk securing the lip stud was responsible for fracturing the buccal cusp of the patient's second premolar.

Perhaps we in the dental profession should warn patients of the potential danger posed by this current fashion.

\section{A. Boistelle \\ London}

\section{Cycling incentives}

Sir, - Colleagues might be interested to know that Avon Health Authority (and presumably there are others similar) pays dentists at the rate of $0.062 \mathrm{p}$ per mile when travelling to postgraduate courses by bicycle.

This should be recognised as a great incentive to leave our car-park-clogging, road-congesting, environment-polluting, noisy motor cars at home.

\section{G. Balfry}

Bristol

Please send your letters to: The Editor British Dental Journal 64 Wimpole Street London WIM 8AL 